\title{
Tensile Capacity of Head-splice Sleeve Connection after a Repeated Axial Stress for Precast Concrete Construction
}

\author{
Sooyeon SEO \\ Dept. of Architectural Engineering \\ Korea National University of Transportation \\ Chungju, Republic of Korea \\ e-mail: syseo@ut.ac.kr \\ Jieun LEE \\ Dept. of Architectural Engineering \\ Korea National University of Transportation \\ Chungju, Republic of Korea \\ e-mail:wldmswkdb@naver.com
}

\author{
Sangku KIM \\ Boowon BMS Co., Ltd \\ Chungju, Republic of Korea \\ e-mail: ibmsbar@naver.com
}

\begin{abstract}
This paper presents the tensile behaviors of HeadSplice Sleeve (HSS) connections after the experience of the low level of repeated axial stresses. HSS is a mechanical connection which was developed to be used for bar connection in precast concrete element. As a required structural capacity of HSS for using in column member, the stiffness degradation should not appear under low stress level of repeated load. Four type of HSS specimen were made for bars of D22, D25, D29, D35 and low cycle test was performed. From the test, it was found that HSS connections have a sufficient strength to induce the bar tensile failure after the experience of a repeated axial loads. The tensile strength of majority of specimens has higher strength than $125 \%$ of design yield strength of bars which is required for mechanical connector in Codes.
\end{abstract}

Keywords-head-splice sleeve (HSS); mechanical connection; low level; repeated axial stresses; tensile strength

\section{INTRODUCTION}

Splice-sleeve connector has been known as a good connecting device for bar connection in the Precast Concrete (PC) system. The most currently used splice-sleeve consists of a separate sleeve for filling of grout mortar and a long sleeve formed for securing the enough embedded length of rebar. Recently, researches have been continued to develop more useful system [1, 2] and the Head-Splice Sleeve (HSS) was developed by Seo et al. [3] as a new type of sleeve system.

In HSS, the separate sleeve for injecting mortar is not necessary because high strength mortar is filled into the sleeve in advance, and it is possible to reduce the development length of rebar as the bond strength is improved due to the head attached to rebar. For the economical and reasonable design of the developed HSS, Seo et al. [3] performed tensile test and suggested a calculation method to calculate its tensile strength.

In case of developing a new type of sleeve, the structural capacity under a repeated axial stress also should be guaranteed since it experiences a repeated tension stress when it is used for the connection of bars in PC columns. In this regard, this paper evaluates the tensile strength of HSS after the experience of a repeated axial stress through an experiment.

\section{HEAD-SPliVE SLEEVE SYSTEM}

As shown in Fig.1, the HSS is composed of small diameter and large diameter portions for the connection of bars. In the large diameter portion, a rebar with a head at the end is inserted along with grout mortar while other rebar is connected in the small diameter portion as in a coupler type. The head of bar contributes to increase the anchorage strength of the bar in sleeve. Therefore, it is possible to reduce the sleeve length in case of using HSS.
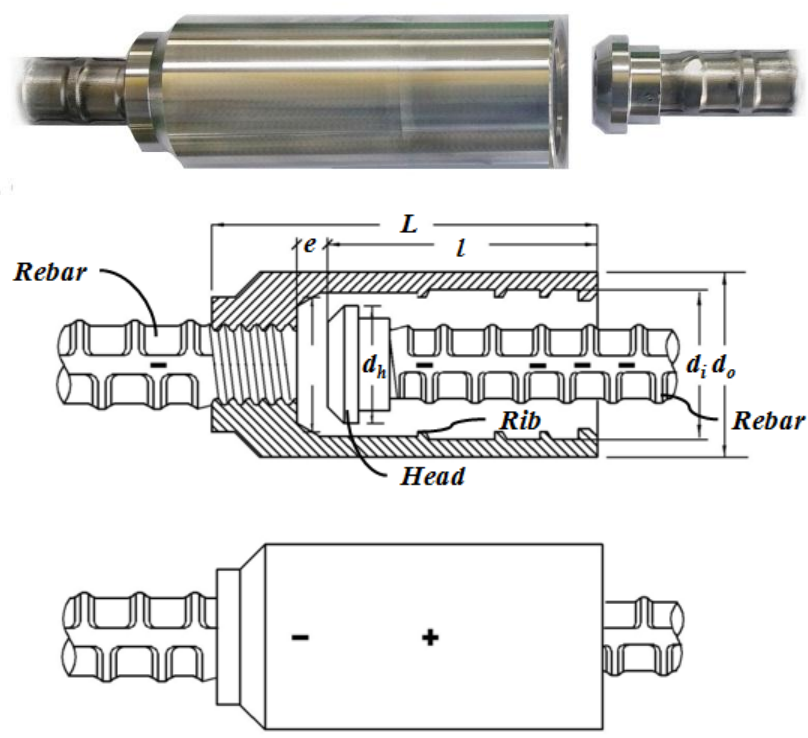

Figure 1. Shape of HSS 


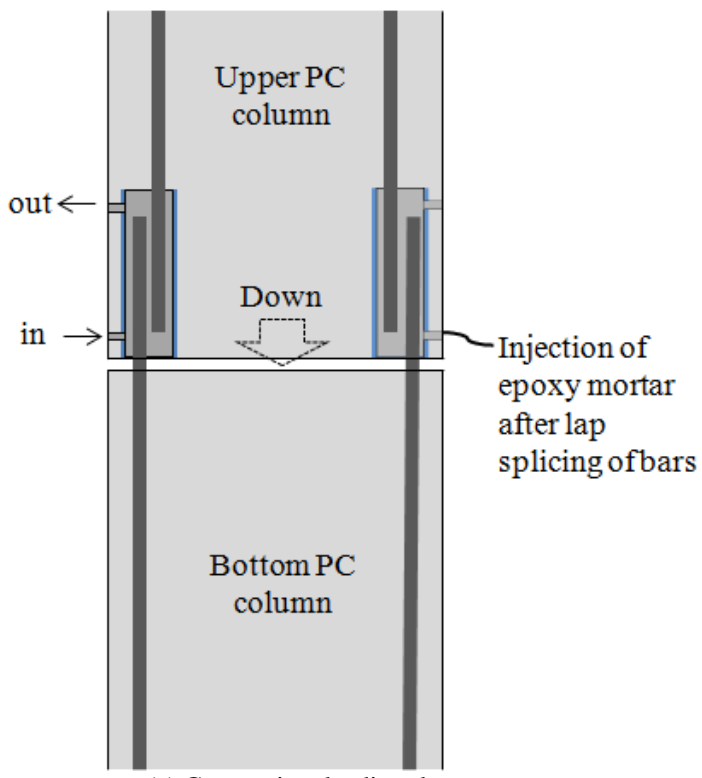

(a) Conventional splice sleeve system

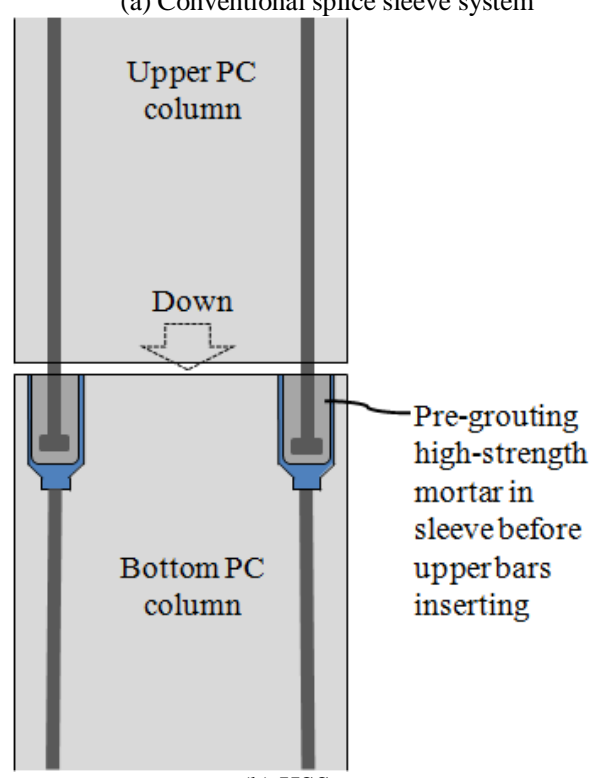

(b) HSS system

Figure 2. Construction process of PC column corresponding to sleeve system

In the construction of precast concrete column at site, the construction process of the connection of bars by using HSS is different to that by conventional one. As shown in Fig.2, epoxy mortar is pre-grouted before inserting of upper bar with head into the sleeve in case of using HSS while epoxy mortar is injected through nozzle after bar lap splicing in case of using conventional one. Therefore, the construction process by using HSS can be simple. However, the diameter of sleeve of HSS is little bit bigger than that of conventional one because of the head. This may cause an increase of space between bars.

The concept of HSS is based on the behavior caused by the bond between the mortar and rebar so that it is very important to calculate the development length based on the bond performance for economical and reasonable design of HSS. In addition, in the design of HSS in which the head is attached to the end of rebar, it is necessary to reflect the anchorage effect of the head embedded in the mortar, which helps to form bearing strength for anchoring, thereby effectively reducing the development length. Even though the HSS needs little bit larger diameter than conventional splice sleeve due to the head, the cross section can be optimized by considering the anchorage effect of the head. In addition, it is possible to get an excellent construction ability and economical efficiency.

\section{TEST METHOD}

HSS connection specimens were made for four size of bar and three specimens were made for each size as shown in Table 1. From the material tests of sleeve and bars, the yield and ultimate strength of sleeve material were 511.75 and $689.8 \mathrm{Mpa}$, respectively. The material properties of each bars were represented in Table 2.

TABLE I. SPECIMEN LIST

\begin{tabular}{|c|c|c|c|c|c|c|c|}
\hline \multirow{2}{*}{$\begin{array}{l}\text { Specimen } \\
\text { Name }\end{array}$} & \multicolumn{4}{|c|}{ Sleeve (mm) } & \multirow{2}{*}{$\begin{array}{l}\begin{array}{l}\text { Head } \\
(\mathrm{mm})\end{array} \\
d_{\text {head }}\end{array}$} & \multirow{2}{*}{$\begin{array}{c}\mathrm{L}_{e} \\
(\mathrm{~mm})\end{array}$} & \multirow{2}{*}{$\underset{(\mathrm{mm})}{\mathbf{L}_{\mathrm{d}}}$} \\
\hline & $L$ & $D_{\text {out }}$ & $D_{\text {in }}$ & $h$ & & & \\
\hline $22-3.4 \mathrm{D}$ & 110 & 50 & 43.4 & 3.2 & 33 & $\begin{array}{c}66.0 \\
(3.0 \mathrm{D})\end{array}$ & $\begin{array}{c}74.8 \\
(3.4 \mathrm{D})\end{array}$ \\
\hline $25-3.5 \mathrm{D}$ & 125 & 57 & 48.5 & 3.5 & 38 & $\begin{array}{c}77.5 \\
(3.1 \mathrm{D})\end{array}$ & $\begin{array}{c}87.5 \\
(3.5 \mathrm{D})\end{array}$ \\
\hline $29-3.6 \mathrm{D}$ & 145 & 65 & 55.3 & 3.9 & 43.5 & $\begin{array}{c}92.8 \\
(3.2 \mathrm{D})\end{array}$ & $\begin{array}{c}104.4 \\
(3.6 \mathrm{D})\end{array}$ \\
\hline $35-3.7 \mathrm{D}$ & 175 & 76 & 65.5 & 4.5 & 51 & $\begin{array}{l}115.5 \\
(3.3 \mathrm{D})\end{array}$ & $\begin{array}{r}129.5 \\
(3.7 \mathrm{D})\end{array}$ \\
\hline
\end{tabular}

TABLE II. MATERIAL PROPERTIES OF BARS

\begin{tabular}{|c|c|c|c|}
\hline Bar & $\mathrm{A}_{\mathrm{b}}\left(\mathrm{mm}^{2}\right)$ & $\mathbf{f}_{\mathrm{y}}(\mathbf{M P a})$ & $\mathbf{f}_{\mathrm{u}}(\mathbf{M P a})$ \\
\hline $\mathrm{D} 22$ & 387.1 & 591.3 & 724.0 \\
\hline D25 & 506.7 & 587.2 & 710.8 \\
\hline D29 & 642.4 & 564.3 & 710.7 \\
\hline D35 & 956.6 & 527.5 & 660.4 \\
\hline
\end{tabular}

Test specimens whose were installed in the $2000 \mathrm{kN}$ UTM as shown in Fig.3 and the distance change between certain points was measured by using two LVDTs during the test. The test was performed by following the procedure for the inspection method of mechanical connection of rebar. As shown in Fig.4, axial load was applied 100 times repeatedly from $5 \%$ of bar yield strength up to $90 \%$ and after that, the tensile load increased until the bar showing fracture. Strain gauges were attached to HSS and both bars to find how much stresses were delivered through the HSS. 


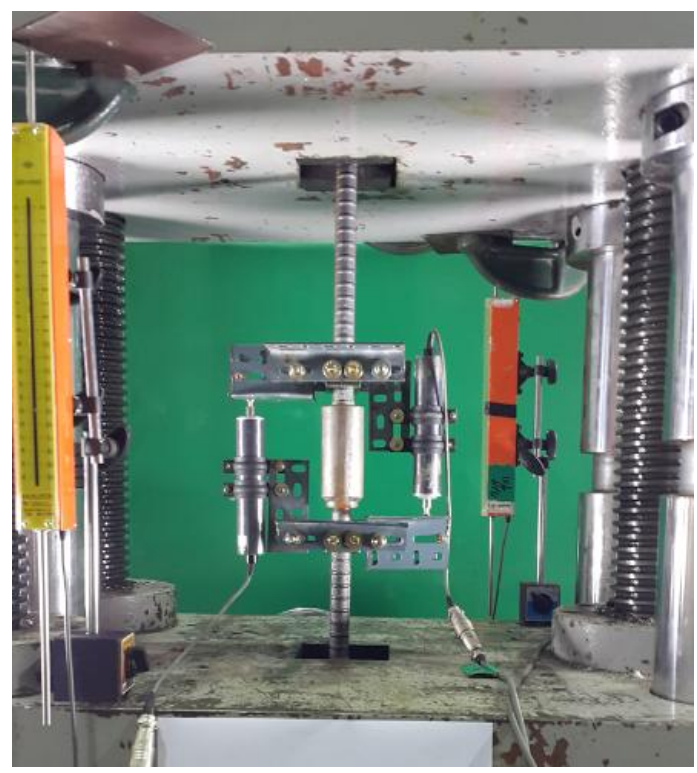

Figure 3. Test setup

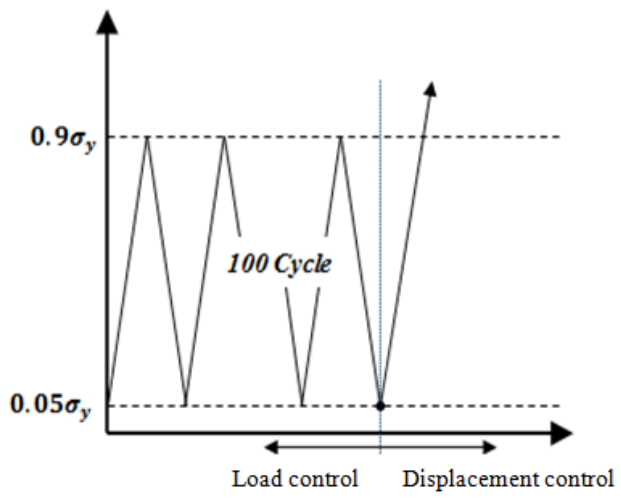

Figure 4. Loading history

\section{TEST RESUlt}

Fig.5 represents the stress-strain curves of all specimens that were drawn from the load-displacement curves. ACI 349 [5] and KBC [6] codify the least strength for mechanical connection that the mechanical connection of bar should have higher tensional strength than $125 \%$ of design yield strength of bar.

For all size of bars, HSS showed similar failure pattern that the mortar crushed and the bar slightly slipped inside sleeve at final stage. Although some of specimens in HD22 and HD25 represented pull out failure, the majority failed by tension failure of bar. The ultimate strengths of all specimens were higher than the $125 \%$ of design yield strength of bars. Form this, it is confirmed that their capacity as mechanical connector satisfy the requirement specified ACI 349 and $\mathrm{KBC}$ code.

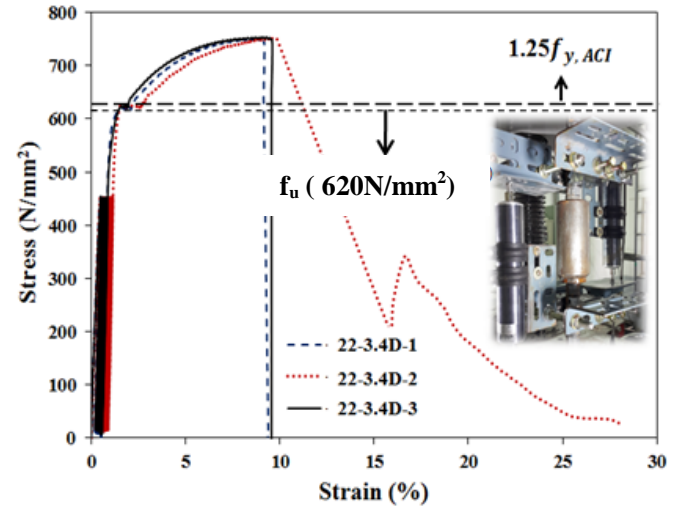

(a) HD22

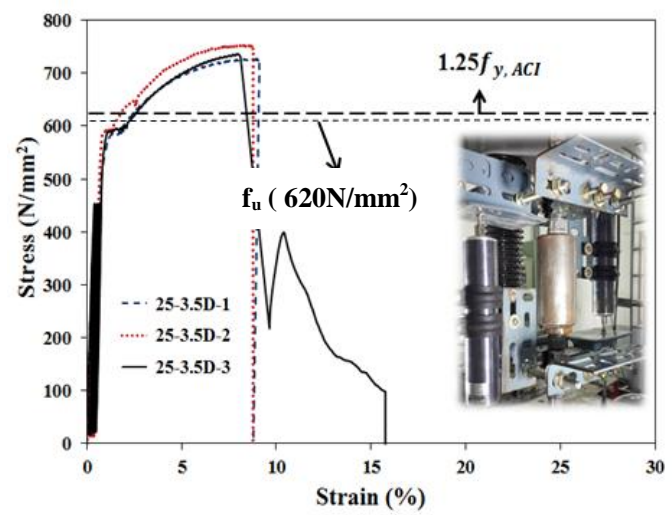

(b) HD25

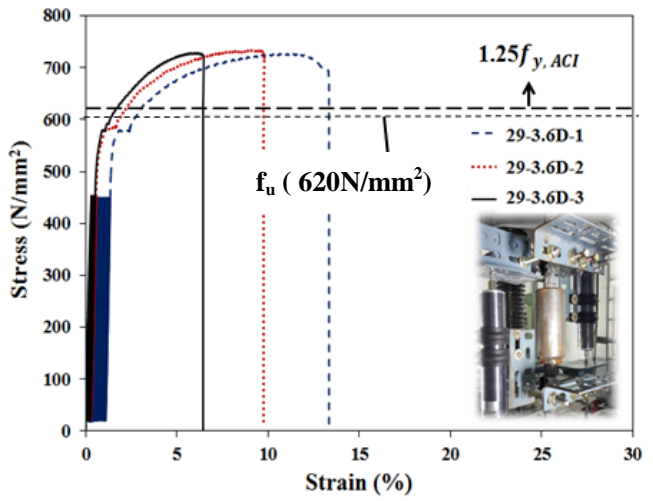

(c) HD29

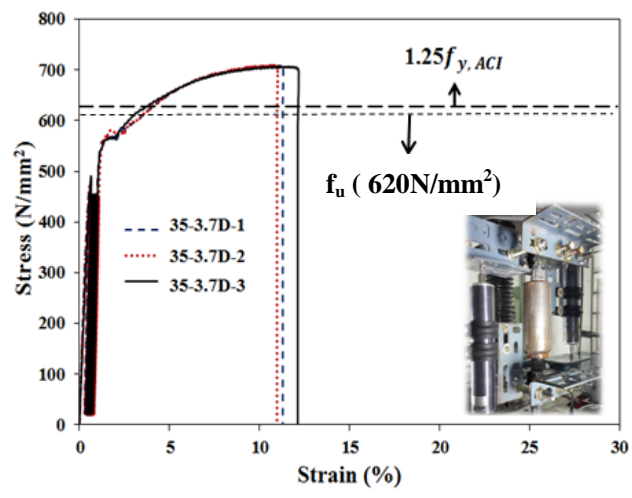

(d) HD35

Figure 5. Stress-strain curves of all specimens 
TABLE III.

TEST RESUlts

\begin{tabular}{|c|c|c|c|c|c|c|c|c|c|c|c|}
\hline \multirow{2}{*}{\multicolumn{2}{|c|}{ Specimen Name }} & \multicolumn{2}{|c|}{$f_{m 1}{ }^{+1}(M P a)$} & \multicolumn{2}{|c|}{$f_{y}^{\star_{2}}(M P a)$} & \multicolumn{2}{|c|}{$f_{u}^{* 3}(M P a)$} & \multicolumn{2}{|c|}{$1.25 f_{y}^{* 4}$} & \multicolumn{2}{|c|}{ Failure mode } \\
\hline & & $T^{* 5}$ & $R^{* 5}$ & \multirow{2}{*}{$\begin{array}{l}T^{\star 5} \\
585\end{array}$} & \multirow{2}{*}{$\frac{R^{* 5}}{622}$} & \multirow{2}{*}{$\begin{array}{l}T^{* 5} \\
676\end{array}$} & \multirow{2}{*}{$\frac{R^{\star 5}}{754}$} & \multirow{2}{*}{$\begin{array}{l}T^{* 5} \\
\text { ok }\end{array}$} & \multirow{2}{*}{$\begin{array}{l}R^{* 5} \\
\text { ok }\end{array}$} & \multirow{2}{*}{$\frac{T^{* 5}}{\mathrm{MF}^{* 6}}$} & \multirow{2}{*}{$\frac{R^{* 5}}{\mathrm{SF}}$} \\
\hline \multirow{3}{*}{$22-3.4 \mathrm{D}$} & 1 & \multirow{3}{*}{62.3} & \multirow{3}{*}{70.9} & & & & & & & & \\
\hline & 2 & & & 589 & 629 & 742 & 752 & ok & ok & MF & MF \\
\hline & 3 & & & 631 & 618 & 742 & 751 & ok & ok & MF & $\mathrm{SF}$ \\
\hline \multirow{3}{*}{$25-3.5 \mathrm{D}$} & 1 & \multirow{3}{*}{62.3} & \multirow{3}{*}{68.6} & 550 & 592 & 682 & 737 & ok & ok & $\mathrm{BF}^{* 6}$ & MF \\
\hline & 2 & & & 552 & 587 & 686 & 754 & ok & ok & $\mathrm{BF}$ & $\mathrm{SF}$ \\
\hline & 3 & & & 552 & 584 & 682 & 728 & ok & ok & $\mathrm{BF}$ & $\mathrm{SF}$ \\
\hline \multirow{3}{*}{$29-3.6 \mathrm{D}$} & 1 & \multirow{3}{*}{73.2} & \multirow{3}{*}{72.9} & 541 & 579 & 668 & 729 & ok & ok & $\mathrm{BF}$ & $\mathrm{SF}$ \\
\hline & 2 & & & 545 & 584 & 667 & 734 & ok & ok & $\mathrm{BF}$ & $\mathrm{SF}$ \\
\hline & 3 & & & 541 & 572 & 665 & 727 & ok & ok & $\mathrm{BF}$ & $\mathrm{SF}$ \\
\hline \multirow{3}{*}{$35-3.7 \mathrm{D}$} & 1 & \multirow{3}{*}{68.0} & \multirow{3}{*}{67.2} & 566 & 563 & 713 & 709 & ok & ok & $\mathrm{BF}$ & $\mathrm{SF}$ \\
\hline & 2 & & & 562 & 575 & 716 & 711 & ok & ok & $\mathrm{BF}$ & $\mathrm{SF}$ \\
\hline & 3 & & & 564 & 563 & 715 & 707 & ok & ok & $\mathrm{SF}$ & $\mathrm{SF}$ \\
\hline
\end{tabular}

*1: Compressive strength of mortar, *2: Yield strength of test result, *3: Ultimate strength of test result, *4: The required strength by code as a mechanical connector,

*5: Test method (T: Result of simple tension test, R: Result of tension test after low level of repeated loads), *6: Final failure type (MF: Mortar failure, BF: Bar failure

In Table 3, results of simple tension test and low cycle repeated load test are represented, respectively. Ultimate strengths from both tests are above the design yield strengths for all size of bars. And majority of them failed by the bar tension failure. From these results, it is confirmed that the HSS connections for the bars of D22, D25, D29 and D35have sufficient structural capacity as the mechanical connection device.

\section{SUMMARY}

In this paper, a series of tensile test of HSS connections experienced a low level of repeated stress was performed to evaluate the structural safety for using precast concrete element of building. Four types of HSS specimens were made for bars of D22, D25, D29, D35 and tensile load applied and increased until failure after the repeated load test.

From the test, it was found that HSS connections have sufficient strength to induce the bar tensile failure after the experience of several repeated axial stress. The tensile strength of majority of specimens has higher strength than $125 \%$ of design yield strength of bars which is required for mechanical connector in Codes.

\section{ACKNOWLEDGMENT}

This work was supported by the Human Resource Training Program for Regional Innovation and Creativity through the Ministry of Education and National Research Foundation of Korea (NRF-2015H1C1A1035953).

\section{REFERENCES}

[1] Amin Einea, Takashi Yamane, Maher K. Tadros, "Grout-Filled Pipe Splices for Precast Concrete Constrution" PCI Jouranl, JanuaryFebruary 1995, pp.82 93.

[2] Jen Hua Ling, Ahmad Baharuddin Abd. Rahman, Izni Syahrizal Ibrahim, Zuhairi Abdul Hamid, "Behaviour of Grouted Pipe Splice under Incremental Tensile Load" Construction and Building Material, Vol. 33, August 2012, pp.90 98.

[3] S. Y. Seo, B. R. Nam and S. K. Kim, "Tensile Strength of the Groutfilled Head-Splice-Sleeve", Construction \& Building Materials, 124, pp.155-166.

[4] ACI Committee, "Splice and Development of High Relative Rib Area Reinforcing Bars in Tension(ACK 408.3-01) and Commentary(ACI 408.3R-01)", ACI, Farmington Hills, 2001, p.6.

[5] ACI Committee 318, "Building Code Requirements for Structural Concrete and Commentary" (ACI 318M-05)", 2005, pp.211-212.

[6] Architectural Institute of Korea, "Korean Building Code and Commentary (KBC 2016)", Kimoondang, 2016. 